\title{
O Homem e a Tabela 1 Dmitri Mendeleev no sesquicentenário da Tabela Periódica
}

\author{
Jorge C. G. Calado \\ Departamento de Engenharia Química, Instituto Superior Técnico, Universidade de Lisboa \\ jcalado@tecnico.ulisboa.pt
}

\begin{abstract}
The Man and his Table - On the International Year of the Periodic Table of Chemical Elements (IYPT2019), a celebration of Dmitri Mendeleev who, more than anyone else, contributed to the establishment of a periodic system of chemical elements 150 years ago. An aperçu of the similarities between the three great founders of modern chemistry, Robert Boyle, Antoine Lavoisier and Dmitri Mendeleev, is followed by an account of the evolution of the notion of chemical periodicity in the $19^{\text {th }}$ century. A biographical sketch shows why Mendeleev should be seen as the true creator of a periodic system of elements among many competitors. His contributions to the development of chemistry and industry in Russia are analysed, as well as the implications of the Periodic Table in science and the arts.
\end{abstract}

\begin{abstract}
A proveitando o Ano Internacional da Tabela Periódica de Elementos Químicos (IYPT2019), celebra-se a vida e a obra de Dmitri Mendeleev que, mais do que qualquer outro cientista - e foram cerca de vinte - contribuiu para o estabelecimento de um sistema periódico de elementos em 1869. Após passar em revista as semelhanças entre os três grandes fundadores da química, Robert Boyle, Antoine Lavoisier e Dmitri Mendeleev, apresenta-se uma breve resenha da evolução da periodicidade química. Apontamentos biográficos tentam explicar porque é que Mendeleev se destacou dos seus competidores para emergir como o inegável criador da Tabela Periódica, tal como hoje é conhecida. São também analisadas as suas contribuições para o desenvolvimento da química e da indústria russa. Na parte final do texto aprecia-se a importância do seu legado, na ciência tal como nas artes.
\end{abstract}

\section{Preâmbulo}

Em 2018 as Boas-Festas chegaram cedo. O meu colega e amigo Santiago Álvarez, distinto catedrático de química inorgânica da Universidade de Barcelona, enviou-me no início de dezembro um cartão festivo anunciando que vinha aí o Ano Internacional da Tabela Periódica (Figura 1)! Esquecemo-nos muitas vezes que além de ser o ADN da Química, a Tabela Periódica é uma riquíssima combinação - única na ciência - de letras e números, que se presta a inúmeros jogos e passatempos. Se um baralho de 52 cartas de quatro naipes pode originar as mais diversas paciências e jogatanas, a Tabela Periódica com 118 elementos é ainda mais viciante. Cabe nela o universo inteiro! Só para dar uma ideia: o número de permutações de 118 elementos ascende a 4,7 x 10 ${ }^{194}$. Se pensavam que o número de Avogadro era inimaginavelmente grande, terão de rever as contas. Para termo de comparação recordo que uma estimativa conservadora do número de galáxias no universo observável aponta para dois triliões, cada uma com uma média de 100 biliões de estrelas - o que perfaz um número total de estrelas da ordem do número de Avogadro. É óbvio que não faz sentido imaginar um composto de 118 elementos; no máximo, haverá meia dúzia de elementos num composto. Por outro lado, as possibilidades de combinação de carbono com hidrogénio são quase inesgotáveis; segue-se o silício como elemento capaz de formar e participar em mais compostos. Ao todo, o número possível de compostos será "biliões e biliões" (para usar uma expressão popularizada por Carl

1 Este artigo é uma adaptação de duas conferências, a primeira proferida na sessão de abertura das XXXII Jornadas de Engenharia Química no Centro de Congressos do IST a 19 de fevereiro de 2019, e a segunda na Ordem dos Engenheiros a 15 de maio de 2019.
Sagan na sua célebre série televisiva "Cosmos", e que deu também o nome ao seu último livro publicado postumamente em 1997).

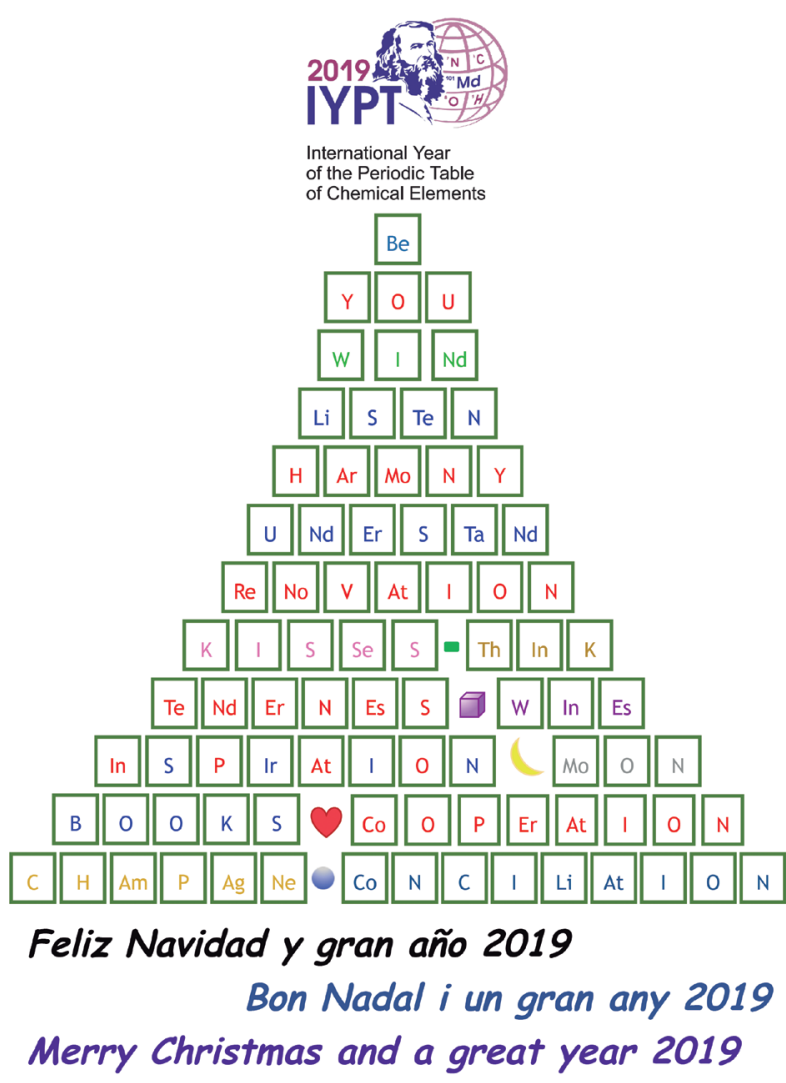

Figura 1 - Árvore de Natal com conceitos baseados na Tabela Periódica, (C) Santiago Álvarez. 


\section{Os três Grandes}

Resumindo a química em três tempos: O pai da química foi Robert Boyle, com a publicação em 1660 das "Novas Experiências Físico-Mecânicas sobre a Mola do Ar e seus Efeitos (Feitas, na sua maior parte, com uma Nova Máquina Pneumática)" e, no ano seguinte, de "O Químico Cético". O padrinho (que batizou erradamente o oxigénio, chamando-lhe gerador de ácidos) foi Antoine Lavoisier, um dos proponentes do novo "Quadro da Nomenclatura Química" (1787) e autor do "Tratado Elementar de Química" dado a lume em 1789. Todavia, quem confirmou a química e deu novos elementos ao mundo antes de serem descobertos foi Dmitri Mendeleev, cujos "Princípios de Química" em duas partes e cinco volumes apareceram entre 1868-1871 (Figura 2).

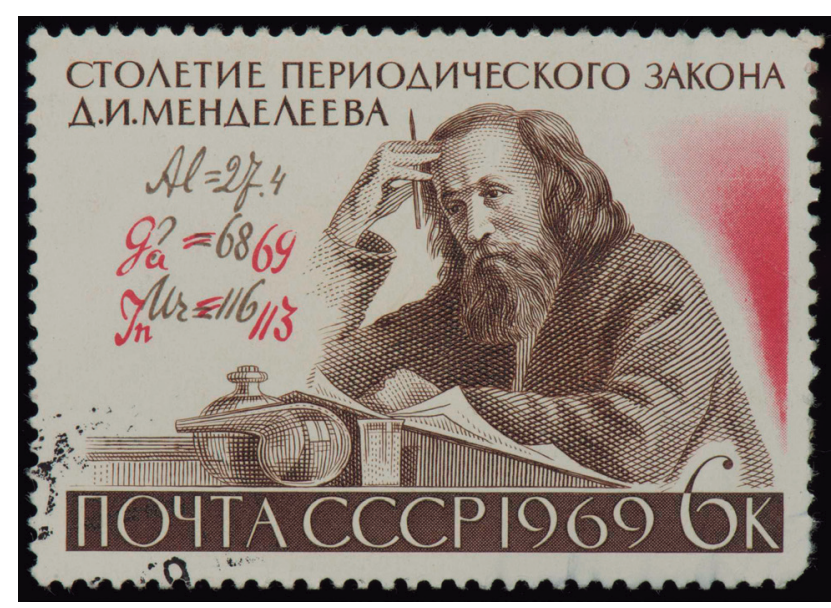

Figura 2 - Selo soviético comemorando o centenário da Tabela Periódica.

À primeira vista os três génios nada têm em comum. Viveram em séculos distintos (XVII, XVIII e XIX), vestiram e pentearam-se de maneira diferente, distinguiram-se por descobertas diversas, nada relacionadas umas com as outras. O primeiro morreu virgem aos 65 anos incompletos; o segundo casou com uma menina quinze anos mais nova e morreu guilhotinado aos 50 anos; o terceiro passou por bígamo e morreu em 1907, aos 73 anos, sem ter ganho o Prémio Nobel. Como cientista, interessa-me mais o que eles tinham em comum, ou não fosse a ciência a arte de descobrir semelhanças entre fenómenos diferentes. Une-os o facto de os três terem vivido em tempos de mudança e de grande turbulência política. Boyle atravessou a Guerra Civil Britânica; Lavoisier viveu e foi vítima da Revolução Francesa; Mendeleev aproveitou as Grandes Reformas Sociais do Czar Alexandre II nos anos 1860, mas teve de sofrer o reviralho do seu filho e sucessor, Czar Alexandre III, um conservador reacionário.

Tanto Lavoisier como Mendeleev envolveram-se diretamente em assuntos e negócios do Estado, e Boyle tê-lo-ia feito também, não fosse a Guerra Civil (1642-1651) e o Protetorado Republicano de Oliver Cromwell. O pai, o irlandês Richard Boyle, Barão de Youghal, Visconde de Dungarvan e Earl of Cork, o súbdito mais rico da coroa britânica, fora um ferrenho apoiante do rei, vindo a perder a fortuna durante a Guerra; Robert era o $14 .^{\circ}$ filho. Lavoisier não só era um fermier-général ou arrendatário do Estado, mas também um membro muito ativo da Academia das Ciências. Especialista em contabilidade, finanças e impostos, chegou a acumular dez cargos governamentais, por exemplo como comissário da Administração Real das Pólvoras e Salitres ou membro da Junta de Diretores da Caixa de Descontos. Aliás, foi a sua experiência como contabilista do deve e haver que o levou a estabelecer a lei da conservação da massa. (Massa, afinal, também significa dinheiro...) De tão ocupado que estava, praticava a química nas horas vagas, isto é, das 6 às 9 da manhã e das 7 às 10 da noite.

Mendeleev, por seu turno, orgulhava-se de servir a pátria em três postos: ensino, investigação e desenvolvimento da indústria química russa. Para ele, não havia distinção entre investigação pura e aplicada. Aliás, era também professor de química tecnológica (desde 1864) no Instituto (Superior) Técnico de São Petersburgo. A ciência era, nas suas palavras, a 'Harmonia da Teoria com a Prática'. "Ser químico não significa necessariamente estar desinteressado de instalações e fábricas e das respetivas condições no país". Como ele notava, "Os olhos de todos os seres vivos apontam para a frente e não para trás", e o futuro estava na industrialização. No entanto, não desprezava a agricultura, então a base da economia russa. Tal como Lavoisier fizera na sua propriedade de Freschines, também Mendeleev praticou uma agricultura racional e científica na sua fazenda de Boblovo, adquirida em 1865. De resto, ainda hoje é considerado o pai da indústria petrolífera russa e o grande remodelador das indústrias do carvão (hulha) e ferro. Como consultor do Czar e do Governo para assuntos científicos e industriais, foi responsável por múltiplas iniciativas, a última das quais a criação (1893) de um Gabinete de Pesos e Medidas que levou à introdução do sistema métrico na Rússia.

Um outro aspeto, não menos importante, liga os três fundadores da química: a cultura e o envolvimento nas artes. Boyle era um escritor notável. Basta mencionar as "Reflexões Ocasionais" (1665), dedicadas à irmã Katharine, amiga do poeta John Milton; foi também o autor do primeiro romance religioso da literatura inglesa, "O Martírio de Teodora e Dídimo", escrito aos vinte anos mas só publicado em 1687, que serviria de base à oratória de George Frederick Handel, "Theodora" (1750). A ligação de Lavoisier à arte é óbvia no retrato do casal pintado por Jacques-Louis David, o maior pintor do seu tempo e amigo dos Lavoisiers. (Ensinara desenho a Marie-Anne.) O casal abria a sua casa aos amigos artistas à segunda-feira à noite - à época, um dos mais bem-frequentados e famosos Salões parisienses. Quanto a Mendeleev, é conhecida a sua grande amizade com o compositor Aleksandr Borodine: encontraram-se em Heidelberg, viajaram juntos pela Europa e juntos participaram no famoso Congresso de Karlsruhe de 1860, onde ficou resolvida a questão dos pesos atómicos dos elementos. O segundo casamento (1882) de Mendeleev, aos 48 anos, com uma jovem pintora e pianista de 22 anos, Anna Ivanovna, levou o casal a colecionar pintura e a criar um Salão em sua casa às quartas-feiras. As ligações artísticas passariam à geração seguinte: a primeira filha, Liubov Mendeleeva, nascida um ano antes do matrimónio, foi das mulheres mais influentes nas artes russas no princípio do século XX. Não só provou ser uma excelente atriz, notável intérprete da Ofélia ("Hamlet"), como se distinguiu como especialista e crítica de ballet. Além disto foi musa dos dois maiores expoentes do Simbolismo russo: 
o poeta Aleksandr Blok (com quem casou em 1903), e o escritor Andrei Bely (com quem viveu uma paixão tumultuosa) (Figura 3).

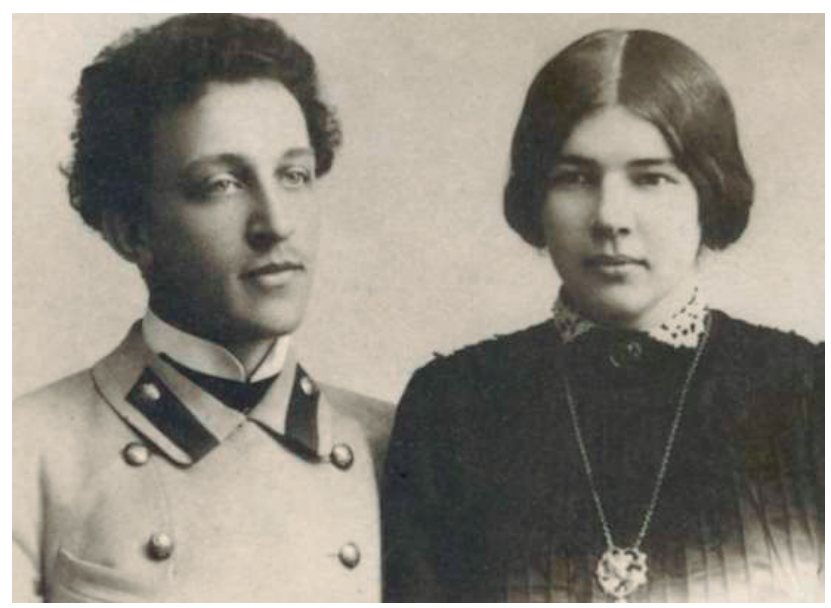

Figura 3 - Aleksandr Blok e Lyubov Mendeleeva.

Nota curiosa: li recentemente uma obra de Bely, "A Sinfonia Dramática" (1902), na qual a escrita assume uma forma e estrutura musicais; o livro inclui também o ensaio justificativo, "As Formas de Arte" (1902), nitidamente influenciado pela química de Wilhelm Ostwald, prémio Nobel de Química em 1909, e assinalável pintor-amador. Era a época em que os químicos abraçavam as artes, e os artistas procuravam a ciência.

\section{Um entre muitos}

Sem desprezar o papel da serendipidade na descoberta científica, noto que há ideias que andam no ar e contaminam vários cientistas simultaneamente - aquilo que se chama Zeitgeist ou espírito dos tempos. Foi assim com o oxigénio na I Revolução Química: descoberto (1771) por Carl Scheele na Suécia, publicado (1774) por Joseph Priestley em Inglaterra, e entendido (1777) por Antoine Lavoisier em França. O mesmo aconteceu com a periodicidade dos elementos químicos em função do peso atómico, uma descoberta inevitável desde que John Dalton propusera a teoria atómica no dealbar do século XIX: toda a matéria é feita de átomos indestrutíveis, existindo tantos tipos de átomos quantos os elementos. Entretanto a noção de peso atómico surge como grandeza relativa, referida ao peso atómico do elemento mais leve, o hidrogénio. O pontapé de saída para o estabelecimento de uma periodicidade química foi dado em 1815 - cinquenta anos antes de Mendeleev se interessar pelo assunto - pelo médico e nutricionista escocês William Prout, ao propor que todos os elementos seriam múltiplos de hidrogénio (o que implicaria que os respetivos pesos atómicos seriam sempre números inteiros). Note-se que isto aconteceu um século antes de se conhecer a estrutura atómica! O átomo de hidrogénio é constituído por um protão e um eletrão, e de facto todos os átomos são constituídos por protões e eletrões, em número igual. O que complicou as coisas foi o desconhecimento da existência de outra partícula nuclear, o neutrão, e portanto da abundância de isótopos. O facto de os elementos poderem existir na forma de vários isótopos (isto é, núcleos com número variável de neutrões) conduz a pesos atómicos que não são números inteiros.
Em 1817, apenas dois anos após Prout ter proposto a sua hipótese, Johann Döbereiner, professor de química da Universidade de Jena, descobria trios de elementos onde o peso atómico do elemento central era a média aritmética dos pesos atómicos dos outros dois. Assim acontecia, por exemplo, com a tríade de cálcio, estrôncio e bário (o que o levou a pensar que o estrôncio pudesse ser uma mistura de cálcio e bário). A ideia das tríades generalizou-se rapidamente e dominou as discussões sobre a periodicidade química durante décadas, nomeadamente graças às sucessivas edições (a partir de 1817) do "Manual de Química Inorgânica" de Leopold Gmelin, professor da Universidade de Heidelberg. Enquanto Döbereiner descobrira quatro tríades, Gmelin conseguiu arrumar cinquenta e cinco elementos num esquema de tríades em forma de V, na edição de 1847 do seu "Manual". Em Paris, Jean-Baptiste Dumas, muito ativo na Academia das Ciências, pensou que o elemento central da tríade fosse um composto dos elementos adjacentes, e chegou a admitir a possibilidade de transmutação (alquímica?) entre os elementos das tríades!

Uma boa parte das dificuldades em chegar a um sistema periódico consistente era devida à inexistência de um conjunto fiável de pesos atómicos dos elementos, que por sua vez dependia da molecularidade das substâncias, isto é, de quantos átomos de cada elemento se juntam para formar a molécula do composto. (Dalton seguira a 'regra da maior simplicidade' ao admitir que em compostos de dois elementos os átomos se combinavam um a um.) Esta questão ficou resolvida com a hipótese de Amedeo Avogadro, publicitada por Stanislao Cannizzaro na já mencionada Conferência Internacional de Química de 1860, em Karlsruhe - o primeiro congresso científico de qualquer disciplina - expressamente convocada para o efeito. Seguiu-se um verdadeiro frenesim ou corrida à periodicidade química, com uma quinzena de cientistas europeus (ingleses, franceses, alemães, russos e até um dinamarquês emigrado na América) a tentar pôr ordem nos mais de 60 elementos conhecidos (Figura 4).

Lista de cientistas que contribuíram para o estabelecimento
de uma periodicidade dos elementos
John Dalton (1766-1844) mestre-escola
William Prout (1785-1850) médico nutricionista
Johann Wolfgang Döbereiner (1780-1849) químico universitário
Leopold Gmelin (178-1853) químico universitário
Adolph Strecker (1822-1871) químico
Peter Kremers (1827-?) químico
Josiah Cooke (1827-1894) cientista universitário
John Gladstone (1827-1902) químico
Ernst Lenssen, (1837-?) químico
John Newlands (1837-1898) químico industrial
Alexandre-Emile de Chancourtois (1820-1886) geólogo
Jean-Baptiste Dumas (1800-1884) académico e político
Max von Pettenkofer (1818-1901) químico e higienista
William Odling (1829-1921) químico
Julius Lothar Meyer (1830-1895) químico universitário
Gustavus Hinrichs (1836-1923) químico e filósofo
Dmitri Mendeleev (1834-1907) químico universitário
Henry Moseley (1887-1915) físico (Número atómico)

Figura 4 - Lista (não-exaustiva) de cientistas que contribuíram para a descoberta da periodicidade dos elementos químicos. 
Houve quem tentasse construir tétradas, e John Newlands, em Londres, foi mais longe com a sua 'lei das oitavas', por exemplo, a sequência flúor, sódio, magnésio, alumínio, silício, fósforo, enxofre e cloro, apresentada em 1865. A analogia musical com o dó, ré, mi, fá, sol, lá, si, dó, talvez inspirada pelo seu correlativo na física - a chamada 'música das esferas' das órbitas planetárias do sistema solar - valeu-lhe a troça de vários colegas que o aconselharam a ordenar os elementos por ordem alfabética para ver se também encontrava novas periodicidades. Houve ainda construções sofisticadas como a de Alexandre-Emile de Chancourtois que em 1862 teve a ideia de organizar os elementos, segundo o peso atómico, ao longo de uma espiral inscrita num cilindro com perímetro de dezasseis unidades, encontrando semelhanças entre elementos em linhas verticais. O problema é que a representação, a que ele chamou 'parafuso telúrico' (por o telúrio ocupar a posição central) (Figura 5) foi omitida na publicação por dificuldades gráficas, e quando finalmente apareceu numa obscura revista geológica, já Mendeleev era reconhecido como o autor da Tabela Periódica. Tal como Mendeleev, também Lothar Meyer estivera presente na Conferência de Karlsruhe. O seu livro "As Modernas Teorias da Química" (1864) incluiu uma tabela de vinte e oito elementos dispostos em grupos por ordem de peso atómico crescente, acompanhada de uma tabela extra de outros vinte e dois, hoje conhecidos como elementos de transição. (Uma versão mais sofisticada da tabela, deixando espaços para elementos desconhecidos, datando de 1868, só viria a lume postumamente, em 1895) Meyer também usou (1870) a valência e o volume atómico para demonstrar inegavelmente a periodicidade química. Não admira que viesse a alimentar uma acesa polémica com Mendeleev quanto à prioridade da descoberta do princípio organizativo hoje conhecido pelo nome de Tabela Periódica.

Será a Tabela Periódica um caso de descoberta coletiva, tão ao gosto de uma certa esquerda científica? Creio que não. Como explicou Isaac Newton, para ver mais longe o cientista apoia-se sempre nos ombros dos gigantes que o precederam ou acompanharam. Por formação e disposição, Dmitri Mendeleev era o químico melhor preparado para ganhar a corrida. Avanço três razões: (i) conhecimento enciclopédico das propriedades dos elementos e dos seus compostos; (ii) temperamento rijo e imaginação adequada à tarefa; (iii) fabulosa capacidade de trabalho e de concentração da mente. Enquanto Lothar Meyer procurou vários caminhos para chegar à periodicidade - valência, volume atómico, etc. - Mendeleev nunca se desviou do peso atómico. Sabia que era praticamente a única propriedade que se mantinha invariável quando os átomos se combinavam para formar moléculas. Por exemplo: um átomo de sódio (metal mole, prateado, tóxico e inflamável) combina-se com um átomo de cloro (gás esverdeado, tóxico) para formar uma molécula de cloreto de sódio ou sal das cozinhas (cristais brancos, essenciais à vida).

O milagre está no funcionamento da Tabela com base no peso atómico. Bem, quando não funcionava, Mendeleev endireitava as coisas, tal era a força das suas convicções. Hoje sabemos que a periodicidade química é uma função do número atómico e não do peso atómico. Todavia, um conjunto notável de coincidências faz com que haja uma proporcionalidade entre as duas quantidades para um número

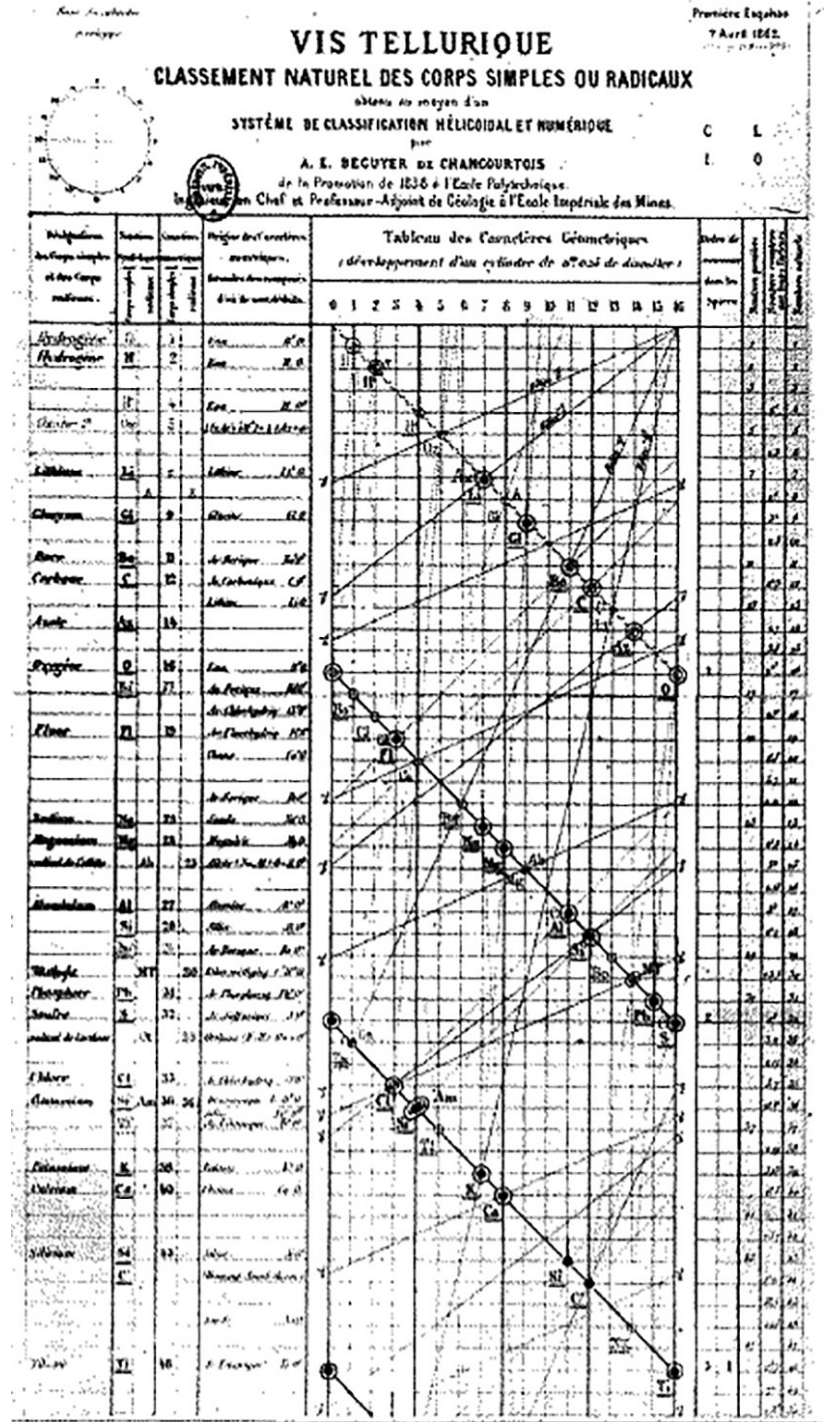

Figura 5 - Parafuso telúrico de Chancourtois.

significativo de elementos comuns. São elas: (i) a massa do átomo está praticamente concentrada no núcleo; (ii) as partículas nucleares, protão e neutrão, têm aproximadamente a mesma massa; (iii) para os elementos mais leves a estabilidade nuclear é assegurada por um número igual de protões e neutrões, o que significa que o peso atómico é aproximadamente o dobro do número atómico (como acontece com o carbono, nitrogénio e oxigénio). Para núcleos mais pesados, a força forte exige maior número de neutrões para vencer a repulsão elétrica dos protões.

\section{A vida atribulada de um jovem siberiano}

Dmitri Mendeleev nasceu perto de Tobolsk, na Sibéria, a 27 de janeiro de 1834 segundo o calendário juliano (que corresponde a 8 de fevereiro no atual calendário gregoriano), no seio de uma família da classe média, o mais novo de dezassete filhos (oito dos quais morreram na infância). O pai, Ivan Pavlovitch, professor secundário de literatura e belas-artes, cegou quando Dmitri era bebé, remetendo-se a casa; a mãe, Maria Dmitrievna, vinha de uma família de industriais. Após a cegueira do marido, tomou conta de uma velha fábrica de vidro da família (onde o jovem Dmitri se entretinha a soprar vidro) e que acabaria destruída por um incêndio em 1849, o ano da morte de Ivan Pavlovitch. 
Reconhecendo a inteligência e a aptidão científica do filho mais novo, Maria pôs-se a caminho de Moscovo com Dmitri e a filha mais nova, Elizaveta, para o matricular na universidade. Uma viagem de mais de 2000 km, a pé e à boleia; as estradas eram rudimentares e o caminho de ferro, um sonho distante. (Não era caso único. Recordo aqui que aos 23 anos, William Murdoch, o futuro inventor da iluminação a gás, também foi a pé da Escócia até Birmingham cerca de 500 km - para pedir emprego a James Watt nas fábricas de fundição de Soho.) Esperava-os a desilusão, pois não havia quota para rapazes da Sibéria! Os Mendeleeves não desistiram. Rumaram de novo à estrada, desta vez em direção à capital, São Petersburgo, a 650 km de distância. Havia bons contactos - Ivan Pavlovitch estudara no Instituto Pedagógico - e Dmitri ficou aqui matriculado. A mãe morreu de exaustão poucos meses depois, com apenas 57 anos, seguindo-se a morte de Elizaveta em 1852, Dmitri ficou sozinho em São Petersburgo.

Os professores do Instituto Pedagógico eram, na generalidade, bons, e vários ensinavam também na Universidade. Dmitri estudou os mais variados assuntos (física, química, biologia, história, educação, pedagogia), formando-se em 1855 com uma dissertação "Sobre o isomorfismo em ligação com outras relações entre as formas cristalinas e respetivas composições químicas" que lhe valeu a medalha de ouro como melhor aluno do curso (Figura 6). Entretanto fora-lhe diagnosticada uma tuberculose e restar-lhe-iam apenas seis meses de vida. Procurou alívio no clima meridional da Crimeia, mas a Guerra de 1854-1856 (que opôs a Rússia à França, Reino Unido, Império Otomano, etc.) obrigou-o a mudar-se para Odessa, na Ucrânia, onde arranjou emprego como professor de liceu. A boa nova foi uma segunda opinião desmentir-lhe o diagnóstico inicial: em vez de tuberculose tinha uma ligeira (e passageira) afeção cardíaca. Nas horas vagas, Mendeleev preparava uma tese de mestrado sobre volumes específicos de soluções. Em 1856 regressava a São Petersburgo e defendia, com êxito, a sua tese na Universidade. No ano seguinte, aos 23 anos, era nomeado encarregado de cursos de química na Universidade de São Petersburgo (sem direito a salário).

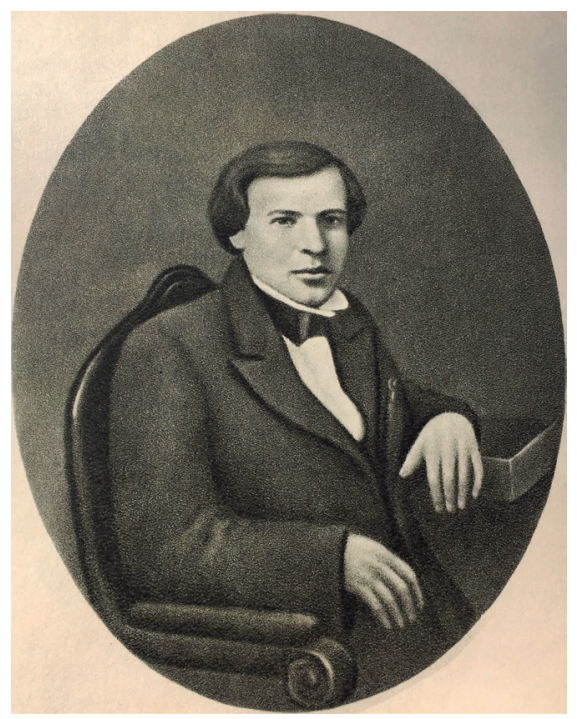

Figura 6 - Dmitri Mendeleev aos 21 anos.

\section{A química de Mendeleev}

O início da carreira académica e de investigação de Dmitri Mendeleev não foi fácil. Para fazer face às despesas tinha que se desdobrar por outras atividades, como a escrita de artigos de divulgação científica e industrial para o Ministério da Instrução Pública. Os laboratórios eram frios, vazios e sem ventilação, inóspitos para qualquer tipo de pesquisa. Em 1859, decidiu partir outra vez, agora com uma bolsa para se aperfeiçoar em Paris (no laboratório de Henri Regnault, professor de física no Collège de France) e na Universidade de Heidelberg (no laboratório de Robert Bunsen). Nessa época, Heidelberg era uma espécie de Meca para as ciências e artes russas. Foi aqui que Mendeleev conheceu o compositor e químico orgânico Aleksandr Borodine (graduado pela Academia Medico-Cirúrgica de São Petersburgo), agora a especializar-se no laboratório de Emil Erlenmeyer. Foi também em Heidelberg que Mendeleev conheceu e se envolveu com a atriz alemã Agnessa Feuchtman, de quem teve uma filha, Rosamunda.

Mendeleev já sabia o que queria e não estava interessado na análise espectral desenvolvida por Bunsen em colaboração com o seu colega de universidade, Gustav Kirchhoff. Também achou os laboratórios mal equipados para o que queria fazer. Resolveu então transformar uma das duas divisões do seu apartamento em laboratório, instalou gás, e encomendou e mandou fazer equipamento segundo as suas instruções. A passagem pelo laboratório de Regnault despertara-lhe o interesse pelas propriedades dos gases e fenómenos como a liquefação. Via semelhanças entre a afinidade química e a coesão molecular, isto é, entre as ligações químicas e as forças intermoleculares. (Curiosamente, no Natal de 1859 Michael Faraday proferia na Royal Institution de Londres as suas célebres lições "Sobre as várias forças da Natureza e relações de umas com as outras" onde tratava da coesão e da afinidade química.) Mendeleev investigou a questão de capilaridade e quis determinar as condições em que a coesão de um líquido se reduz a zero num tubo de vidro hermeticamente selado. À respetiva temperatura chamou 'temperatura absoluta de ebulição'. Percebeu que para liquefazer os chamados gases permanentes (hidrogénio, nitrogénio, etc.) não bastaria aumentar a pressão; seria também necessário baixar a temperatura. Por outras palavras, antecipava em dois ou três anos a investigação de Thomas Andrews sobre a liquefação de dióxido de carbono e respetivo ponto crítico. Em 1861 Mendeleev regressava a São Petersburgo para retomar a sua atividade pedagógica na universidade, e no ano seguinte casava com Feozva Lechtcheva - uma união arranjada pela irmã mais velha, Olga. O casamento (que produziu dois filhos) não foi feliz. Passados poucos anos, o casal já vivia vidas separadas e distantes.

Na universidade, Mendeleev ensinava química orgânica (ao mesmo tempo que, para sobreviver, traduzia livros técnicos alemães e dava aulas de química tecnológica a futuros engenheiros ou aos cadetes do exército). Insatisfeito com os livros existentes, publicou um "Compêndio de Química Orgânica" (1861) que recebeu os aplausos da crítica e dos estudantes, e acabaria premiado pela Academia Russa de Ciências. Mendeleev era, aliás, um excelente pedagogo que usava a ironia para despertar o interesse dos estudan- 
tes: comparava, por exemplo, o hidrogénio ao ouro, por serem ambos elementos elusivos, que desaparecem rapidamente... Nas aulas falava de tudo, relacionando a química com os temas mais variados, da geologia à meteorologia e cosmogonia, da agricultura à fisiologia, até à música e pintura! Para tese de doutoramento, regressou à investigação das propriedades das soluções, nomeadamente das misturas de álcool e água. Desenvolvera, aliás, um picnómetro especial para as estudar. A natureza e estrutura das soluções líquidas permaneceria um dos seus grandes interesses científicos ao longo da vida. Aquele que ele considerava o trabalho mais importante, "Investigações sobre as soluções aquosas segundo o seu peso específico" (1887), onde analisava o comportamento das soluções de 283 substâncias em função da concentração e da temperatura, foi dedicado à memória da mãe. (A propósito: vinha ainda longe o entendimento das ligações de hidrogénio: anos 1920, na sequência dos trabalhos de G. N. Lewis.) Doutorado em 1865, dois anos depois ascendia à cátedra de química inorgânica.

Ao contrário dos nossos contemporâneos, como professor e investigador Mendeleev servia, acima de tudo, a sua universidade e a sua pátria. Por exemplo, aproveitou a nova autonomia universitária para transformar os laboratórios de São Petersburgo no maior centro de investigação química da Rússia. Ao aperceber-se das notáveis contribuições de Aleksandr Butlerov, professor na Universidade de Kazan, para o estabelecimento da química orgânica estrutural moderna, não descansou enquanto São Petersburgo não o contratou (1868), mesmo sabendo que ele próprio deixaria de reger a cadeira. Em 1869 foi também instrumental na contratação de Nikolai Menshutkine como professor de química analítica.

Sob vários aspetos, Mendeleev era um visionário que antecipava o futuro. Via a ciência como o grande motor do desenvolvimento industrial e económico (o que o colocou em oposição ao seu grande contemporâneo, o romancista Lev Tolstoy, que abominava o progresso industrial). Teve a sorte de estar ativo no tempo certo. As 'Grandes Reformas' do Czar Alexandre II nos anos 1860 (emancipação dos servos, novo estatuto para as universidades, criação dos conselhos rurais, reforma da justiça, relaxamento da censura, autonomia municipal, etc.) permitiram-lhe intervir, com sucesso, a nível governamental. Embora rica em matérias-primas, a Rússia continuava a ser um país agrícola com técnicas arcaicas. Mendeleev estava determinado a transformar o caráter da economia do seu país e a puxá-la para a fase industrial. Simultaneamente com o ensino e a investigação, o desenvolvimento da indústria química russa seria - nas suas palavras - o seu "terceiro posto ao serviço da pátria".

Os interesses maiores centraram-se no petróleo. Aos 29 anos visitou as explorações petrolíferas de Baku, à beira do Mar Negro, e em 1876 viajava até à América para conhecer as instalações petrolíferas da Pensilvânia (não ficou impressionado com o capitalismo americano). A excursão resultou na publicação de "A indústria do petróleo no estado norte-americano da Pensilvânia e no Cáucaso" (1877). Em 1867 fez parte da comissão que organizou a representação russa na Exposição Universal (de Artes e Indústria) em Paris. Nunca mais parou. Ele foi o aproveitamento da hulha da bacia do rio Donetz e a possível gaseificação do carvão subterrâneo (1888), o fabrico da pólvora sem fumo no princípio dos anos 1890, a indústria de ferro nos Urais (em 1899, já sexagenário), a modernização dos sistemas de transportes e a eventual construção de canais para ligar as indústrias do ferro às do carvão, etc.

\section{A Tabela Periódica de Mendeleev}

É tempo de voltar a 1867, quando aos 33 anos, Dmitri Mendeleev atingiu o topo da carreira académica na Universidade de São Petersburgo, pronto para ensinar química inorgânica. Tal como fizera meia dúzia de anos antes quando era professor de química orgânica, impunha-se escrever um livro. O resultado seria o colossal "Princípios de Química" em duas partes e cinco volumes, publicado entre 1868-1871. Tinha agora que trabalhar com mais de sessenta elementos! Como pôr ordem nesta salgalhada de compostos e propriedades? Qual o princípio organizativo mais lógico? Para a $1 .^{\mathrm{a}}$ parte, que tratava dos elementos mais comuns (hidrogénio, oxigénio, nitrogénio e carbono) e terminava com os halogéneos (flúor, cloro, bromo e iodo), resolveu tomar a valência como indicador. A 2. ${ }^{\text {p par- }}$ te, que incluía os metais e as terras raras, exigia critérios simultaneamente mais rigorosos e subtis. Muitos elementos tinham valências variáveis. Mendeleev pôs-se às cavalitas dos seus antecessores e viu melhor e mais longe. Por exemplo, percebeu que a analogia de propriedades (periodicidade) acontecia aos 'saltos' (como nas tríades de Döbereiner ou nas oitavas de Newlands) e igualmente para elementos com pesos atómicos parecidos (como era o caso do ósmio, irídio e platina). O Sistema Periódico - como inicialmente lhe chamou - seria pois uma tabela (a princípio) de colunas verticais (séries) e linhas horizontais (famílias).

Pela primeira vez na história da periodicidade, (quase) tudo parecia fazer sentido. Não só conseguiu arranjar lugar para os 63 elementos conhecidos (embora com dúvidas em relação a meia-dúzia deles, porventura por dispor de pesos atómicos errados), como pôde melhorar o peso atómico de alguns por interpolação dos pesos atómicos de elementos adjacentes. Teve ainda a coragem de trocar as posições do telúrio e iodo (apesar de este último apresentar um peso atómico inferior ao primeiro); mais tarde, duplicaria o peso atómico do urânio de 120 para 240. Noutros casos deixou espaços para elementos que faltava ainda descobrir e que completariam a periodicidade, por exemplo, "elementos análogos ao alumínio e ao silício com pesos atómicos entre 65-75", que viriam a ser o gálio (descoberto em 1875), e o germânio (em 1886). Por uma circunstância fortuita sabe-se o dia do nascimento da Tabela Periódica: 1 de março de 1869 (ou, no calendário juliano então ainda em vigor na Rússia, 17 de fevereiro). Nesse dia Mendeleev era suposto ir inspecionar uma fábrica de queijos, mas cancelou a visita de tão entusiasmado que estava a completar o seu novo Sistema (Figura 7).

Da posse de um sistema periódico consistente, Mendeleev enviou cópias da Tabela a duzentos químicos (entre Russos e estrangeiros), redigiu uma comunicação à Sociedade Russa de Química (que cofundara no ano anterior), fez comunicações a congressos e redigiu vários artigos, tudo em 1869, aos 35 anos de idade (Figura 8)! Para Mendeleev, a Tabela era um "work in progress". Aperfeiçoou-a ao longo da vida à medida que se corrigiam os valores dos 


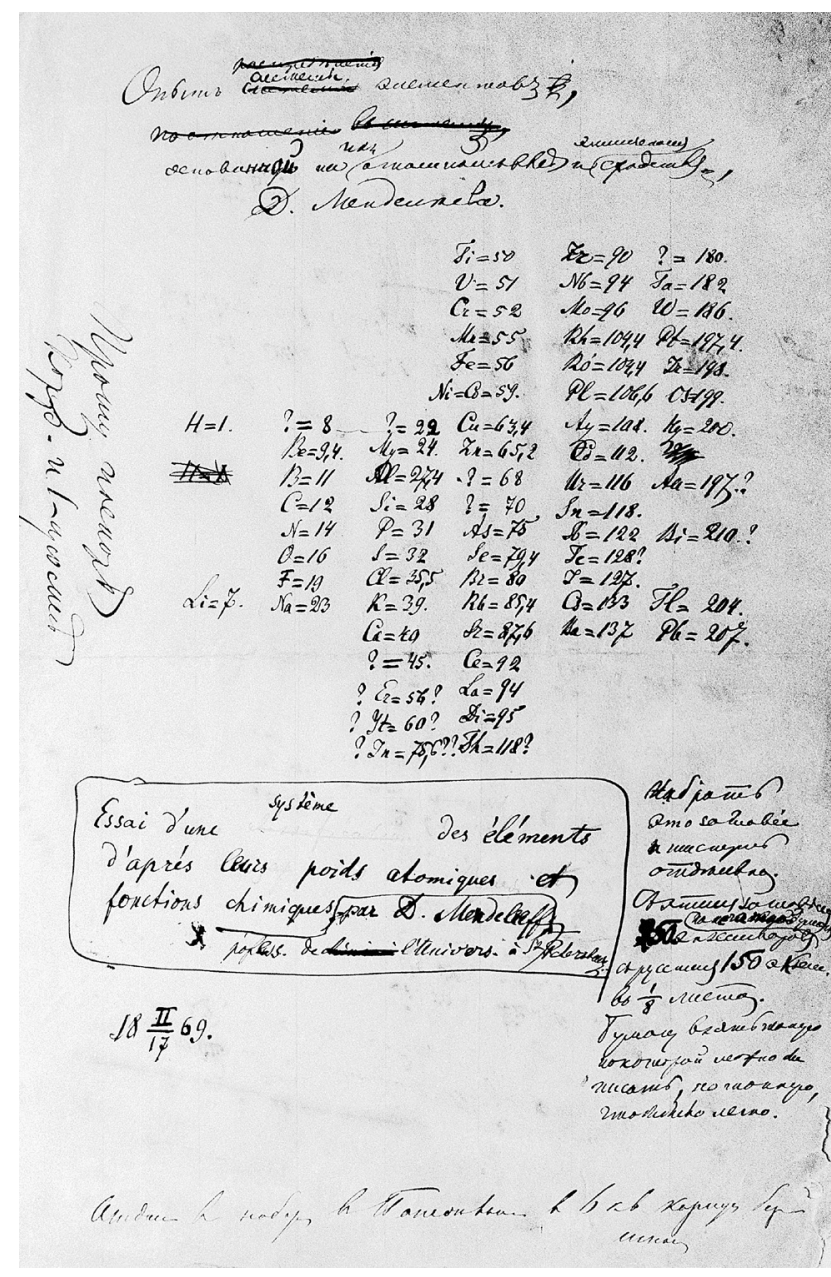

Figura 7 - Primeiro rascunho da Tabela Periódica (1/março/1869).

pesos atómicos ou se descobriam novos elementos (caso dos gases nobres hélio e árgon). Experimentou vários formatos, curto e estendido e até o helicoidal (introduzido por Chancourtois). Publicou cerca de trinta variantes e deixou outras tantas na forma de manuscrito. Quanto aos "Princípios de Química", foram um sucesso editorial que passou por muitas edições. A 5 . $^{\text {a }}$ edição, publicada em 1889 , foi traduzida em alemão, francês e inglês e selou a celebridade internacional do seu autor. Ainda hoje é considerado um livro-chave na história da química. No seu livro de memórias, "O meu tio Tungsténio", o neurologista Oliver Sacks considerou-o o "mais delicioso e brilhante livro de química jamais publicado".

\section{A segunda vida de Mendeleev}

Separado há anos de Feozva, em 1878 Mendeleev resolveu pedir à irmã, Ekaterina, para se lhe juntar em São Petersburgo, a fim de lhe governar a casa. Ekaterina trouxe os filhos, mas com ela veio também uma bonita jovem de dezanove anos, Anna Ivanovna Popov, estudante de belas-artes e amiga de uma das filhas. Foi paixão à primeira vista (embora Dmitri tivesse mais do dobro da idade de Anna). Mendeleev divorciou-se de Feozva em 1881 e no ano seguinte casou com Anna Ivanovna (de quem já tinha uma filha, Lyubov). Para efeitos legais, Dmitri era um bígamo, pois a lei russa só permitia um segundo casamento seis anos após o divórcio do primeiro. Quando avisaram o Czar da complicada situação marital do seu conselheiro, este terá respondido: "Sim, ele terá duas mulheres, mas eu só tenho um Dmitri Mendeleev!"
ОПЫТ'Ъ СИСТЕМЫ ЭЛЕМЕНТОВЪ,

ОСНОВАННОЙ НА ИХЪ АТОМНОМЪ ВЪСЪ И ХИМИЧЕСКОМЪ СХОДСТВЪ.

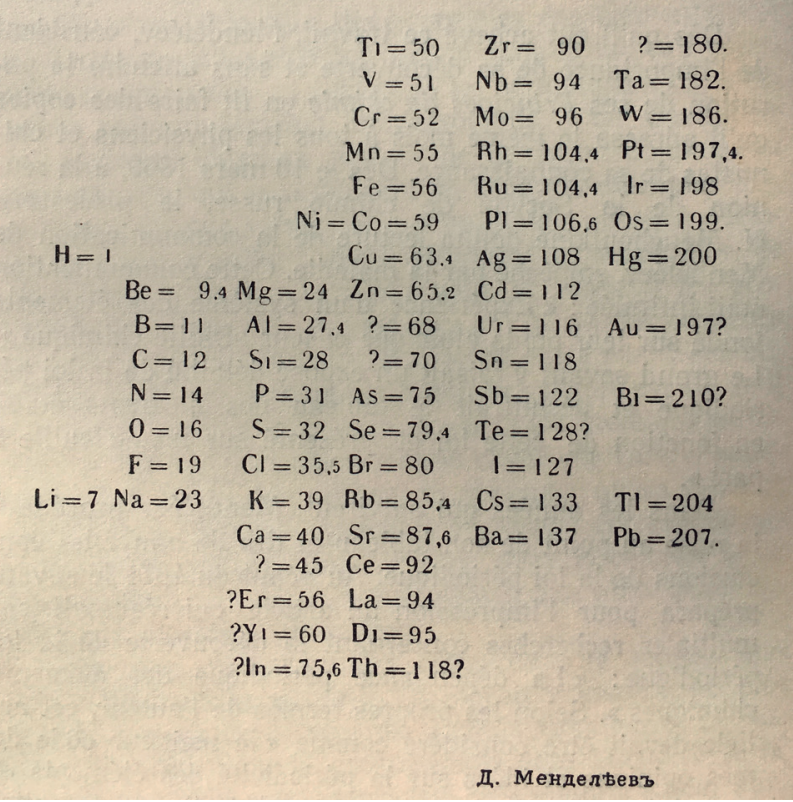

Figura 8 - Circular da Tabela enviada a 200 químicos.

Com uma mulher jovem e bonita, com talento para a música e pintura, Mendeleev tornou-se muito mais sociável. Abriu a casa aos amigos às quartas-feiras à noite, criando um Salão muito popular entre músicos como Borodine e os seus colegas do chamado Grupo dos Cinco (Mussorgsky, Balakirev, Cui e Rimsky-Korsakov) e pintores como Ilya Repine (que pintaria o seu famoso retrato envergando o traje doutoral da Universidade de Edimburgo em 1885). Anna Ivanovna era, aliás, uma pintora talentosa, como mostra o retrato (inacabado) que fez do marido (Figura 9). Pelo seu lado, Mendeleev tornou-se um importante crítico de pintura, a ponto de ser eleito para a Academia Russa das Artes em 1894. (Tinha falhado a eleição para a Academia Imperial das Ciências em 1880, em sucessão ao seu velho mestre Nikolai Zinine, por causa da sua complicada situação marital.)

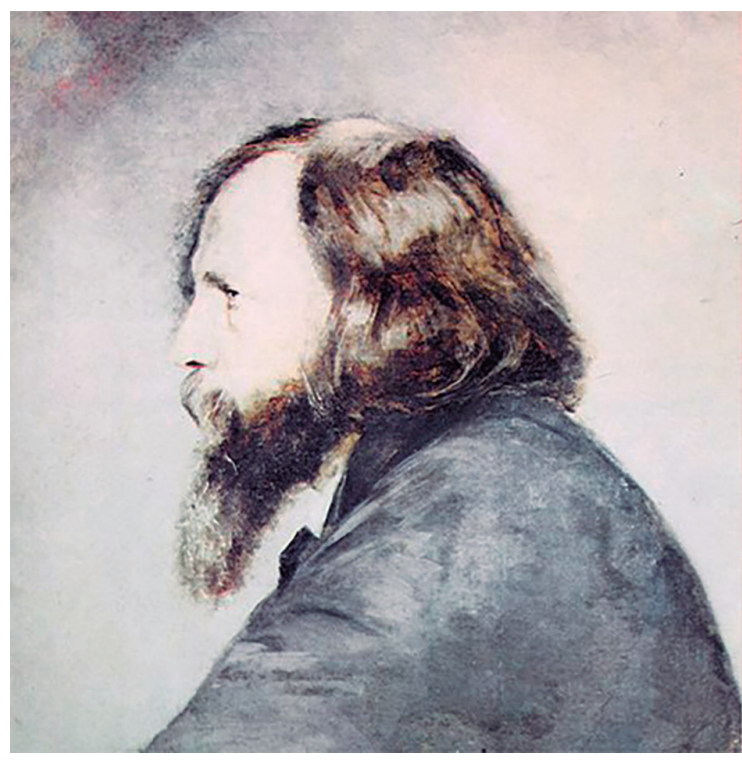

Figura 9 - Retrato (inacabado) de Dmitri Mendeleev por Anna Ivanovna, 1885. 
Infelizmente o Czar fora assassinado em 1881, e o sucessor, Alexandre III, revelou-se um monarca autoritário e repressivo. Na crise estudantil de 1890, Mendeleev tomou o partido dos estudantes e enviou uma carta de protesto ao ministro (que se recusou a aceitá-la). Mendeleev demitiu-se imediatamente de professor da universidade, embora continuasse a colaborar com as autoridades na sua qualidade de conselheiro de Estado. Na cátedra de química inorgânica sucedeu-lhe Nikolai Menshutkine (que nesse mesmo ano inventaria a reação que permite transformar uma amina terciária num sal de amónio, e que hoje leva o seu nome.) Em 1893 Mendeleev era nomeado diretor do recém-criado Gabinete Russo de Pesos e Medidas onde introduziria o sistema métrico, embora a título facultativo (Figura 10). Homenageado por todas as nações cultas da Europa (doutoramentos Honoris causa, medalhas, condecorações, etc.), Dmitri Mendeleev falhou o Prémio Nobel, instituído em 1901. Sabe-se que foi nomeado em três anos consecutivos: 1905 (ano em que o prémio foi atribuído a Adolf von Baeyer pelo seu trabalho com corantes orgânicos e compostos hidroaromáticos), 1906 (perdeu por um voto a favor de Henri Moissan que isolara o flúor em 1886) e 1907 (o ano em que faleceu). A desculpa foi que o prémio se destinava a investigações recentes e a Tabela Periódica já tinha quase quarenta anos. O verdadeiro motivo foi a oposição obstinada do químico sueco Svante Arrhenius, nobelizado em 1903, que nunca perdoara a Mendeleev a crítica às suas teorias de dissociação iónica. O genial autor da Tabela Periódica morreu a 2 de fevereiro de 1907, tendo sido sepultado no cemitério de Volkovo, em São Petersburgo, ao lado da mãe (Figura 11).

\section{Legado}

Passaram 150 anos, mas o legado de Dmitri Mendeleev não cessou de aumentar e de se valorizar. Hoje pode ser representado por uma Tabela de 118 elementos, finalmente completa (Figura 12). Um deles, o n. ${ }^{0} 101$ (uma capicua!) tomou o nome de mendelévio. Vejo aqui um hemiciclo onde está representado tudo aquilo que existe: nós, o Everest, o Sahara, a Amazónia ou a Antártida; a Lua, Júpiter e Titã (o satélite de Saturno que é, até hoje, o corpo celestial mais distante explorado diretamente). Em 2004, a sonda Huygens (da missão Cassini) atitanou com êxito, revelando que o planeta tem nuvens, chuva, lagos e rios de misturas de hidrocarbonetos leves, e até um oceano subterrâneo de água salgada. Vejo aqui um parlamento onde esquerda e direita estão condenadas a entender-se (até porque se atraem): à esquerda, os elementos eletropositivos, que gostam de perder eletrões; à direita, os elementos eletronegativos que preferem adquirir eletrões. Elementos alcalinos e ácidos, separados pela imparcialidade dos chamados gases nobres. É este tipo de raciocínio que explica o facto de tantos políticos importantes serem químicos. O primeiro presidente do Estado de Israel, Chaim Weizmann, era professor de química na Universidade de Manchester; Mrs Thatcher e Frau Merkel formaram-se em química; Maria de Lurdes Pintassilgo, a primeira mulher em Portugal a assumir as funções de primeiro-ministro, era engenheira química. Mais: em Portugal tivemos dois comissários europeus, um presidente da Assembleia da República, meia dúzia de ministros (educação, negócios estrangeiros, etc.) que eram ou tinham sido químicos ou engenheiros quí-

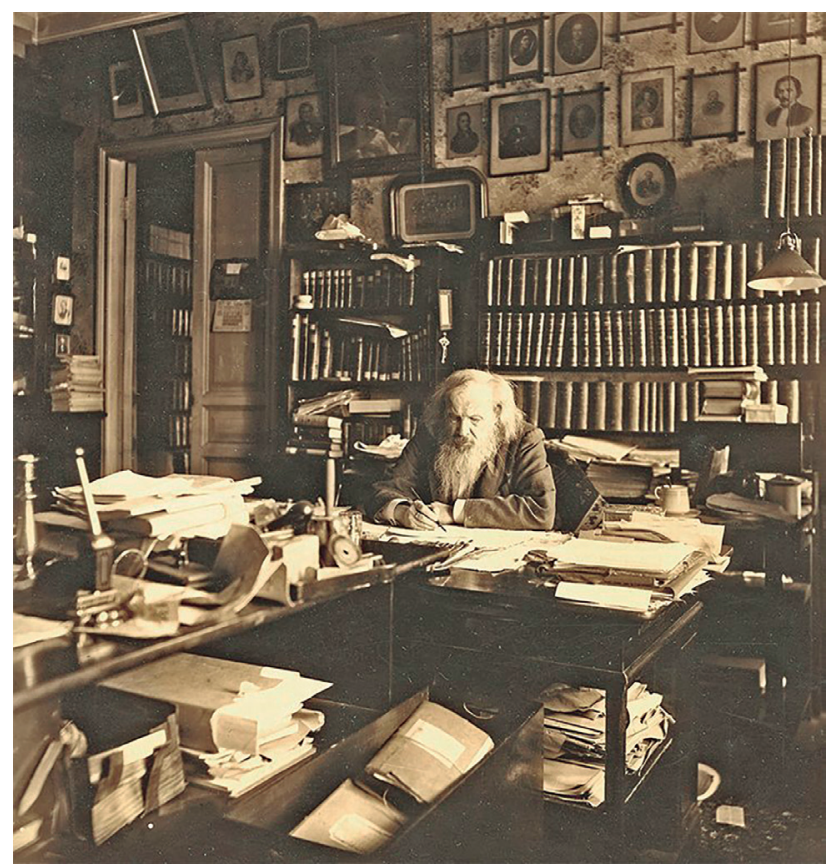

Figura 10 - Dmitri Mendeleev no seu escritório do Gabinete de Pesos e Medidas, ca. 1900.

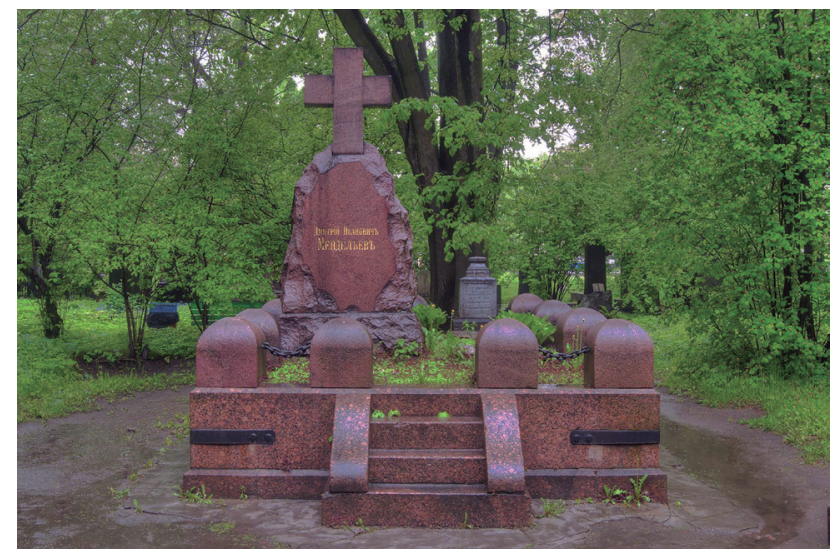

Figura 11 - Túmulo de Mendeleev no cemitério de Volkovo.

micos. O Papa Francisco estudou química e trabalhou num laboratório antes de entrar para o seminário.

Mendeleev acreditava no papel da química como ciência central. Em 1905, já no fim da vida, afirmava: "Química moderna não é um simples jogo de palavras; é a realidade que governa toda a investigação, todas as análises e sínteses da química. Possui o seu próprio microcosmos em áreas invisíveis, e na sua qualidade de ciência ultrarreal trabalha constantemente com as suas partes invisíveis sem as considerar mecanicamente inseparáveis. Os átomos e as moléculas que inevitavelmente se tornaram o objeto de estudo de todas as áreas da mecânica e da física, não podem ser outra coisa senão os átomos e partículas determinados pela química, tal como requerido pela unidade de pensamento". Há 150 anos, Dmitri Mendeleev pôs a química na ordem. Como ciência central que usa a física para explicar a biologia, a química é quem mais ordena.

Confesso que a minha admiração por Mendeleev roça a idolatria. Recordo o espanto e maravilha que senti quando no $10 .^{\circ}$ ano aprendi a história da periodicidade dos elementos. Aluno do Instituto Superior Técnico, decorei a Tabela Periódica com todo o gosto - nomes dos elementos e respe- 


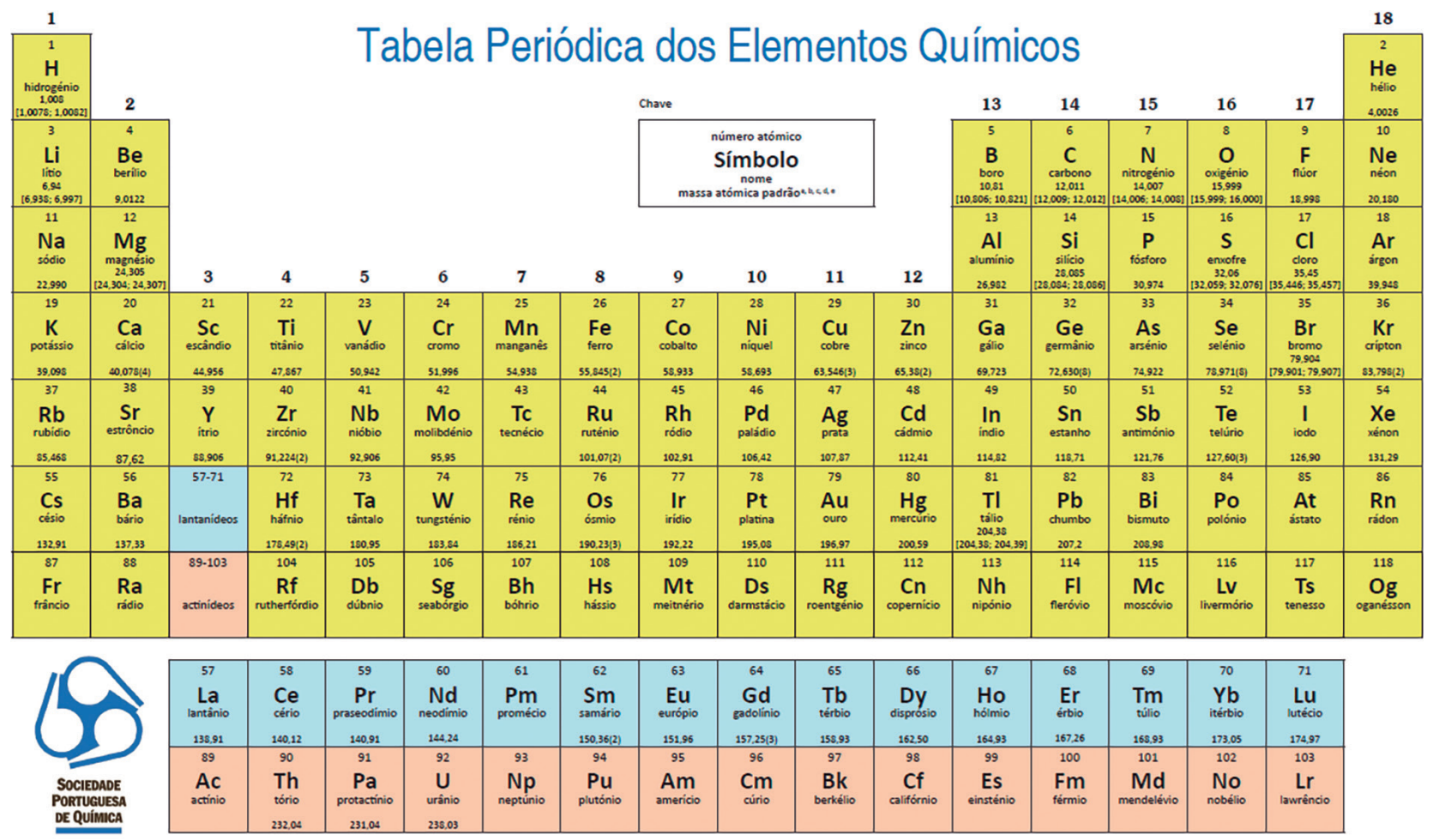

Figura 12 - Tabela Periódica (SPQ).

tivos lugares - e nunca mais a larguei. Acompanhou-me ao longo da vida, no trabalho e no lazer. Encontrei-a por todo o lado, nas mais diversas formas. Por exemplo, na canção de Tom Lehrer, 'Os Elementos', muito popular nos meus tempos de estudante do Técnico; na literatura, com a obra-prima de Primo Levi, "O Sistema Periódico" (1975), que termina com um ponto final de carbono; até nas formas arquitetónicas de Steven Holl, como o Simmons Hall, uma residência para 350 estudantes do MIT. (Bem, a Tabela Periódica tem apenas 118 quartos...)

Para mim, a dádiva maior de Mendeleev foi poder usar a Tabela Periódica como um Palácio de Memória - um edifício com mais de uma centena de salas onde posso guardar ideias e factos que não quero esquecer. Trata-se de uma técnica ancestral de memorização, que remonta aos Gregos. Foi assim que Matteo Ricci, um jesuíta italiano que estudou em Coimbra e passou por Macau, conquistou ideologicamente a China no final do século XVI. Não só memorizou milhares de carateres chineses, como era capaz de os escrever e debitar de trás para a frente e da frente para trás, ou por qualquer ordem previamente determinada. Por outras palavras, a Tabela Periódica permitiu-me inovar no meu trabalho e ainda hoje me ajuda a pensar e a "navegar por estranhos mares de pensamento".
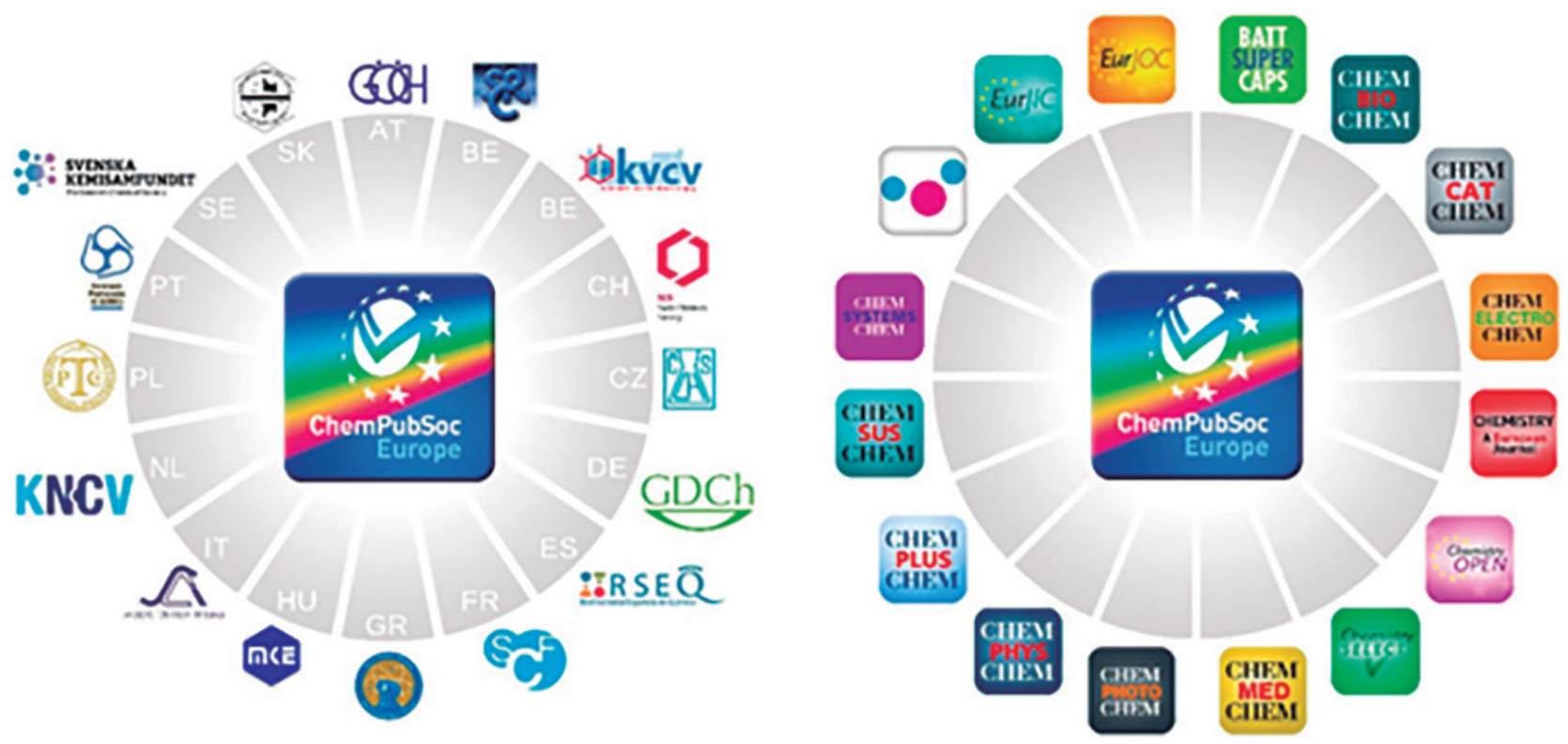